\title{
Is there evidence for a set point that regulates human body weight?
} Manfred J Müller ${ }^{1}{ }^{*}$, Anja Bosy-Westphal ${ }^{1}$ and Steven B Heymsfield ${ }^{2}$

\author{
Addresses: ${ }^{1}$ Institute of Human Nutrition and Food Science, Christian-Albrechts University, Düsterbrooker Weg 15-17, 24221 Kiel, Germany; \\ ${ }^{2}$ Pennington Biomedical Research Center, Baton Rouge, LA 70808, USA \\ * Corresponding author: Manfred J Müller (mmueller@nutrfoodsc.uni-kiel.de) \\ FI000 Medicine Reports 2010, 2:59 (doi:10.3410/M2-59)
}

The electronic version of this article is the complete one and can be found at: http://fl000.com/reports/medicine/content/2/59

\begin{abstract}
There is evidence for the idea that there is biological (active) control of body weight at a given set point. Body weight is the product of genetic effects (DNA), epigenetic effects (heritable traits that do not involve changes in DNA), and the environment. Regulation of body weight is asymmetric, being more effective in response to weight loss than to weight gain. However, regulation may be lost or camouflaged by Western diets, suggesting that the failure of biological control is due mainly to external factors. In this situation, the body's 'set point' (i.e., a constant 'body-inherent' weight regulated by a proportional feedback control system) is replaced by various 'settling points' that are influenced by energy and macronutrient intake in order for the body to achieve a zero energy balance. In a world of abundance, a prudent lifestyle and thus cognitive control are preconditions of effective biological control and a stable body weight. This idea also impacts future genetic research on body weight regulation. Searching for the genetic background of excess weight gain in a world of abundance is misleading since the possible biological control is widely overshadowed by the effect of the environment. In regard to clinical practice, dietary approaches to both weight loss and weight gain have to be reconsidered. In underweight patients (e.g., patients with anorexia nervosa), weight gain is supported by biological mechanisms that may or may not be suppressed by hyperalimentation. To overcome weight loss-induced counter-regulation in the overweight, biological signals have to be taken into account. Computational modeling of weight changes based on metabolic flux and its regulation will provide future strategies for clinical nutrition.
\end{abstract}

\section{Introduction and context}

Since body weight is a major determinant of health, the regulation and preservation of body composition are life-saving issues. The central nervous system and peripheral systems regulate energy and nutrient balance by biological and behavioral mechanisms. Short-term controls include the initiation and termination of feeding (e.g., brought about by gastrointestinal signals), whereas long-term control of body weight is related to changes in energy balance and energy stores. Efficiency of body weight regulation is dominated by both sides of the energy balance (both energy intake and energy expenditure), which are functionally interconnected. Thus, increases in either food intake or energy expenditure are associated with corresponding changes in metabolism and behavior. Overeating is followed by increases in thermogenesis, whereas increases in energy expenditure (e.g., due to strenuous exercise) affect food intake. The general idea is that human body weight is under sufficiently strong genetic and humoral control, a view inspired by the theory of the so-called 'set point'. This theory proposes a proportional feedback control system designed to regulate body weight to a constant 'body-inherent' weight, namely the set point weight [1]. The system, according to this theory, adjusts food intake or energy expenditure (or both) in proportion to the difference between the current body weight and the set point weight. The set point theory originated from animal studies [2] and ever since has been questioned in humans. 
Many people appear to have a constant body weight throughout adult life. However, intervention studies suggest that a set point in humans is 'loose' (e.g., involving upper and lower limits) rather than tightly controlled [3]. In the classical Minnesota starvation study [4], the subjects lost $66 \%$ of their initial fat mass in response to 24 weeks of semi-starvation (i.e., at $50 \%$ reduced energy intake), but ad libitum re-feeding resulted in a regain of fat mass reaching $145 \%$ of the pre-starvation values (i.e., there was an overshooting of fat mass, known as the catch-up fat phenomenon) [5]. Thus, the fluctuation in body weight that results from under- and overfeeding requires a considerable change in the hypothetical set point, at least after starvation, re-feeding, and overeating. Alternative models of body weight regulation therefore (a) involve multiple body weight steady states, so-called 'settling points', without a feedback control of energy intake [1] or (b) propagate an asymmetric or threshold control system that responds to negative energy balance only [2].

Further simulation of the Minnesota starvation experimental data suggested that after re-feeding, it may take more than a year for the fat mass to decrease to within $5 \%$ of the initial value $[6,7]$. These data point to a transient loss in appetite control (and thus body weight regulation) during the first months of re- and overfeeding. Returning to a pre-starvation (and presumably healthy) lifestyle may take longer time periods as the body reconstitutes or resets its body weight regulatory system. This finding may lead to the more general hypothesis that the biology of body weight regulation is camouflaged by hyperphagia (and presumably a Western lifestyle).

Control of energy intake is a complex topic and this control is something that many overweight people lose in the long term. This is reflected by nearly all of the weight loss experiences of obese patients who typically lose their diet adherence with time [8]. Obviously, at reduced body weight, a new set or settling point is hard to establish (or hard to defend). It has been calculated that in weightreduced obese patients, maintenance of lost body weight would have been achieved if energy intake over the course of 2 years had been $170 \mathrm{kcal} /$ day $(0.7 \mathrm{MJ} /$ day $)$ lower than before dieting [7]. The failure of keeping these small changes in diet, and thus of maintaining a reduced weight, may be taken as evidence for the inaccuracy or even inefficiency of our weight control system to defend the 'new' settling point. Alternatively, the programmed regaining of body weight may also be taken as evidence for a high set point, which seems to be well defended in most obese patients.
The data from randomized controlled pharmacological weight loss trials question the existence of a body weight control system. When compared with dietary restriction alone, a cannaboid-1 receptor blocker caused significant weight loss over the course of 2 years $(-6.3 \mathrm{~kg}$ versus $-1.6 \mathrm{~kg}$ compared with pre-study weights) [9]. However, patients who were switched from the drug to the diet group in the second year of the protocol regained weight and reached nearly identical weight losses after the second year $(-2.7 \mathrm{~kg}$ versus $-2.9 \mathrm{~kg}$ by diet alone compared with pre-study weights) [9]. These data may be taken as evidence for different settling points. Alternatively, weight changes simply followed energy intakes (which were lower during drug treatment than during diet alone) and the final body weights then reflected a new and zero energy balance.

There are some lines of evidence suggesting that the traditional set point theory seems to be overly simplistic. The present article sets out to address the following questions:

1. Is there evidence for a set point in body components (rather than in body weight)?

2. Is there a 'set' in energy balance and macronutrient metabolism?

3. Is leptin a body weight regulatory signal, and what is the evidence for asymmetric control of body weight?

4. Does a Western lifestyle camouflage biological regulation of body weight?

\section{Recent advances}

Recent advances arose from the area of detailed body composition research and from recent findings on the genetic, epigenetic, and endocrine control of body weight (i.e., leptin as part of the body weight regulatory system). To put these data into perspective, the new results have to be discussed within the context of some older results from integrative physiology which have frequently been neglected in modern research on genetic control of body weight.

The contribution of gene variants to body weight regulation is currently estimated to be small, and most genome-wide association results are for markers that are not in known genes [10]. In addition, metabolic programming and epigenetic influences add to body weight regulation. The developmental origins of the health and disease hypothesis (i.e., the fetal programming hypothesis) speculate that maternal over- and undernutrition affect the in utero environment thereby inducing fetal adaptive responses favoring long-term and 
permanent changes in hypothalamic circuits of appetite regulatory centers, post-natal overnutrition, and excess weight gain in the offspring [10]. Genomic imprinting (including DNA methylation and histone modification) results in later discordance between metabolic responses anticipated by the program and the environment. This idea is supported by a recent study that found that, when comparing the offspring of obese mothers with those of obese mothers who had lost weight following biliopancreatic bypass surgery, the prevalence of offspring who were overweight was reduced by $52 \%$ after maternal biliopancreatic bypass surgery [11]. These data point to the role of epigenetic factors in the regulation of body weight.

A major recent advance is computational modeling of weight changes based on metabolic fluxes and their biological control. This will add to future strategies of pharmacological and non-pharmacological treatment of clinical problems of being over- or underweight. Today, it seems likely that the phenotype (i.e., an obese body mass index [>30]), influenced by set or settling points, is the product of genetic effects (DNA), epigenetic effects (heritable traits that do not involve changes in DNA), and the environment.

\section{Is there evidence for a set point in body components rather than for body weight?}

Body weight is heterogeneous in that it comprises many different organs and tissues. In a two-compartment model, body weight is the sum of body fat mass and lean or fatfree mass. Lean mass consists of bone, extracellular water, and body cell mass; body cell mass includes intracellular water, glycogen, and protein. Anatomically, lean tissue comprises a number of individual organs or components such as skeletal muscle, liver, brain, heart, and kidneys. In a 70-kg male, these components make up 40\%, 2.6\%, $2.0 \%, 0.5 \%$, and $0.4 \%$ of body weight, respectively [12]. Some component weights are interrelated (e.g., there is a positive correlation between muscle mass and bone mass), but for other components (including bone and brain), their weights are not associated with each other [13]. This lack of association argues against a common regulation of the mass of individual organs and tissues and therefore overall body weight. Instead, it appears more likely that individual organ and tissue mass are differently regulated.

Body weight regulatory feedback may originate from fat mass $[2,5]$. Both surgical lipectomy and transplantation of white adipose tissue in animals result in compensatory changes to defend total body fat [14]. In the Minnesota study, post-starvation hyperphagia was related to the extent to which body fat was depleted $[4,5]$, suggesting that the drive to overeat is part of a regulatory system that operates to restore fat mass. In addition, there is sufficient evidence for humoral feedback signals that influence body fat mass, and studies of extreme human obesity phenotypes (i.e., children who are obese from a very early age) suggest that the efficiency or inefficiency with which these processes operate may be heritable [15]. However, adipose tissue is heterogeneous with respect to location, amount present, metabolic functions, and response to weight changes $[16,17]$. This concept implies that a search for regulation of individual adipose tissue depots rather than of total body adipose tissue is necessary. There is some recent evidence suggesting that adipose tissue distribution is genetically (or epigenetically) programmed [18]. Diet-induced weight loss in overweight subjects does not affect adipose tissue distribution, implying that the different depots (e.g., visceral and subcutaneous) are reduced with weight loss $[16,17,19]$. However, there are preferential losses of visceral adipose tissue [20] and ectopic fat in the liver and these are disproportionately depleted with weight loss [17].

\section{Is there $a$ 'set' in energy balance and macronutrient metabolism?}

Increasing energy expenditure can increase energy intake, whereas increasing energy intake does not intrinsically increase activity and energy expenditure [21]. However, with strenuous exercise and very high energy expenditure, energy intake cannot be adjusted adequately and the energy balance becomes negative [22]. Metabolic compensation is obvious during controlled under- and overfeeding (i.e., during rapid changes from energy equilibrium to a negative or positive imbalance) [23-25]. With underfeeding and weight loss, total (i.e., 24-hour) energy expenditure (TEE), resting energy expenditure (REE), the thermic effect of meals, and physical activity (PA) decrease [4,6,24-26], whereas increases in TEE and REE (but not PA) are observed in response to overfeeding and weight gain $[6,23,25,27]$. Metabolic changes exceed changes in metabolically active tissue mass (i.e., they were not explained by changes in body mass) and thus are partly due to decreasing or increasing the rate of cellular respiration. The wholebody metabolic response to under- and overfeeding is brought about by an interplay of metabolic rates in individual organs (e.g., heart, liver, kidneys, skeletal muscle, and brain), and this again is explained by changes in sympathetic nervous system activity, in plasma concentrations of thyroid hormones and leptin, and in insulin sensitivity $[7,28]$. These metabolic adaptations aim at diminishing the energy imbalance (to finally reach a new equilibrium between energy intake and energy expenditure) and thus add to longterm weight stability [29]. This idea argues in favor of a 'set' to reach zero energy balance at a given body weight, 
which results in various settling points rather than a set point.

In regard to the comparison of different energy stores, fat, protein, and carbohydrate stores differ with respect to both (a) magnitude (i.e., in a 70-kg male, about 140,000 kcal [or $586 \mathrm{MJ}$ ] as fat, 24,000 kcal [100 MJ] as protein, $600 \mathrm{kcal}$ [2.5 MJ] as carbohydrate) and (b) regulation [29]. In the long term, carbohydrate balance is tightly regulated and a glycogen feedback signal acts to correct glucose oxidation and thus carbohydrate imbalances $[23,30]$. Thus, a minor decrease in liver glycogen (e.g., brought about by a low-carbohydrate, high-fat diet) increases the eating drive in order to replenish glycogen stores (which will also take a large amount of fat and thus increase fat mass in the case of a low-carbohydrate, highfat diet) [31]. By contrast, protein and fat imbalances are not tightly counter-regulated, leading to greater losses or gains in these individual components in response to nutrient intake. Whole body and cellular uptake of dietary carbohydrates, fat, and protein is matched by their rates of use. There is a hierarchy of post-prandial substrate oxidation, and fat intake did not stimulate fat oxidation $[32,33]$, and this explains large fluctuations in fat mass in response to varying fat intakes [33]. Taken together, these data suggest that carbohydrate balance, rather than protein and fat balance, is regulated as part of a putative body weight regulatory system. If glycogen stores serve as a 'set' for body weight, then variation in body weight is a reflection of the fat content of the diet rather than of an active regulation.

\section{Is leptin a feedback signal of body weight regulation? What is the evidence for asymmetric control?}

During the last 15-20 years, the progress in our understanding of the neurobiology of appetite and satiety has led to the characterization of fascinating networks of hormones, peptides, and monoamines as part of the appetite control system. However, endogenous control of energy intake is still not completely characterized and external factors (i.e., the obesity-promoting environment) may override endogenous controls. It is unknown at present how biological factors (e.g., hormones) combine with external factors (e.g., food supply) to control food intake. In addition, the impact of metabolic adaptation on energy and macronutrient intake remains to be characterized.

Most of the recent research on body weight regulation is based on the idea that brain centers, including those located in the hypothalamus, receive peripheral signals reflecting energy and fat stores. Early parabiosis studies gave the first strong evidence that genetically obese mice lacked a secretory signal from adipose tissue which represses food intake [34]. One relevant homeostatic signal in body weight (or fat mass) regulation is the prototype adipokine leptin $[35,36]$. Leptin is derived from fat cells in proportion to fat mass, and one of leptin's tasks is to send signals regarding levels of fat mass (or changes in fat mass) to the hypothalamus, which in turn regulates both a decrease in energy intake and an increase in energy expenditure. This is an example of proportional feedback control, as food intake and energy expenditure are adjusted in proportion to the difference between plasma leptin concentration and its set point value [1]. However, present evidence suggests that leptin does not primarily protect the body against an increase in fat mass but instead defends the body against fat loss, thus operating in cases of negative energy balance only (i.e., there is an asymmetric or threshold response to leptin at low concentrations only) $[2,37,38]$.

Low levels of leptin, indicating food deprivation and depleted fat stores, are a signal to induce adaptive biological actions leading to an increase in energy intake (which cannot or does not happen in the case of food shortage or eating disorders) and to reduce energy expenditure $[39,40]$. For example, the correlation line demonstrating the relationship between leptin and REE, adjusted for fat-free mass, is steep at low leptin levels and flat at normal leptin levels, suggesting that the effect of leptin on REE differs at different leptin concentrations with a thermic effect at low concentrations only [40]. This example highlights that the control of individual body component mass (e.g., fat) depends on energy balance and may be efficient in response to negative energy balance and fasting only. An asymmetric control system is in line with the experience that it is easier to gain weight than to lose weight. While the latter is tightly controlled, the former seems to be not fully compensated. This idea also questions the hypothesis that leptin resistance, as suggested by high-plasma leptin levels, causes obesity.

\section{Does a Western lifestyle camouflage biological regulation of body weight?}

Observational and experimental human data give some evidence for biological control of body weight. However, given the present obesity epidemic, this may reflect a collective overwhelming of the biological body weight control systems. In fact, biological 'brakes' are considered to be weak and do not really operate within an obesitypromoting environment. This failure is part of the socalled 'runaway weight gain train' model that has been proposed to perpetuate obesity and to further accelerate the obesity epidemic [41]. However, on a daily balance, excess weight gain is a failure in the fine tuning of energy balance, and obesity results from a chronic (but small) 
positive energy balance. The so-called energy gap (i.e., the daily imbalance between energy intake and energy expenditure, resulting in excess weight gain) is about $50-150 \mathrm{kcal} /$ day ( 0.2 to $0.6 \mathrm{MJ} /$ day) only (corresponding to $5 \%$ of daily energy intake) $[42,43]$. This is in line with longitudinal data showing that a difference in energy expenditure of about $70 \mathrm{kcal} /$ day was associated with differences in weight gain [44]. All of these data point to the need of precise matching between energy intake and energy expenditure. Thus, a mismatch between the two suggests that regulation is not precise. Some of the metabolic changes observed in overweight subjects (e.g., increases in energy expenditure and fat oxidation) contribute to limiting further weight gain in response to chronic overeating and aim to reach a new steady state (i.e., at a settling point) rather than to re-establish initial body weight [29]. It is obvious that under Western lifestyle conditions, compensatory responses are passive rather than active and thus have a limited impact on body weight regulation.

It is tempting to speculate that imperfect body weight control is due to our present lifestyle habits, which offset biological control. This idea is in line with animal studies in which so-called cafeteria (or Western) diets resulted in hyperphagia (i.e., the animals lost intake control), progressive weight gain, and obesity when compared with a normal chow diet [45]. Switching back again to a chow diet, the rats normalized their body weights (i.e., the animals readjusted their weights to previous levels), and in the long term, this resulted in a normal weight trajectory [45]. This is in line with human data showing that energy-dense foods, which are rich in fat and sugar, cause 'passive' overeating and thus weight gain [46]. By contrast, an ad libitum, low-fat, high-carbohydrate, traditional diet led to a spontaneous return to habitual energy intake (within 3 months) and a recovery of initial body weight (within 2.5 years) after massive overfeeding, with $19 \pm 3.2 \mathrm{~kg}$ weight gain in lean young Cameroonian men [47]. A set point regulation was also evident under a traditional low-fat diet and seasonal fluctuations (caused by an annual food shortage) in the body weight of rural Gambian women [48]. Despite repeated weight cycling over a period of 10 years, minimal body weight remained fairly stable (within $\pm 1.5 \mathrm{~kg}$ ).

\section{Implications for clinical practice}

In regard to clinical practice, dietary approaches to both weight loss and weight gain have to be reconsidered. In the underweight patient, weight gain is supported by biological mechanisms that might be suppressed in part by aggressive hyperalimentation. By contrast, to overcome weight loss-induced counter-regulation in the overweight, biological signals (i.e., the weight loss-associated decrease in plasma leptin and T3 [triiodothyronine] levels) have to be taken into account. Evidence suggests that leptin replacement may help to reconstitute biological control. In addition, modeling of weight changes (e.g., in patients with cachectic cancer) [49] based on biological control of body weight provides new concepts in pharmacological and non-pharmacological treatment of the underweight.

\section{'Set point and settling points' instead of 'set point versus settling point'}

Taken collectively, these data provide evidence for the idea that there is biological (active) control of body weight and also weight stability (and thus a set point at a healthy steady state) in response to eating healthy chow diets. By contrast, this regulation is lost or camouflaged by Western diets, suggesting that the failure of biological control is due mainly to external factors. In this situation, the set point is replaced by various settling points that are influenced by energy and macronutrient intake in order for the body to reach a zero balance of energy and macronutrients and thus a new and possibly unhealthy steady state. Western diets may have a higher risk in subjects who are efficient in the intake or metabolism of food energy, the so-called thrifty genotypes, who have been proposed to have a genetic predisposition or a high set point. However, the present evidence from integrative physiology leads to simple rather than to sophisticated answers. In a world of abundance, a prudent lifestyle and thus cognitive control (i.e., 'from instinct to intellect') [50] are preconditions of efficient biological control, a stable body weight, and thus maintenance of a set point. This idea is true even in those people who may have an efficient intake or metabolism of food energy (i.e., the thrifty genotype) [10] since the putative mutation is effective at high energy and fat intake only. In this sense, losing one's set point (or ending up in various settling points) of body weight may serve as another example of the 'mind-body paradigm' (e.g., in the obese, there is a 'mind-body gap' and thus a loss of biological control). This idea also impacts future research on body weight regulation. Searching for the genetic background of excess weight gain in a world of abundance is misleading since the possible biological control is widely overshadowed by the effect of the environment. As a consequence, environmental factors rather than the physiology (including the genetic background) have to be addressed to tackle population-wide, non-syndromic human obesity. It is interesting to note that the fundamental components of energy balance, including the effect of the environment, are well preserved across species. For example, canine obesity is closely associated with snack eating and low socioeconomic state, suggesting that the overweight issue is not a uniquely human problem [51]. 


\section{Abbreviations}

PA, physical activity; REE, resting energy expenditure; TEE, total energy expenditure.

\section{Competing interests}

The authors declare that they have no competing interests.

\section{Acknowledgments}

Our own data were supported by 'Competence Network on Obesity', funded by the Federal Ministry of Education and Research (FKZ: 01GI0821) and the Deutsche Forschungsgemeinschaft (German Research Foundation) (DFG Mü 714/8-3 and DFG Bo3296/1-1).

\section{References}

I. Hall KD, Heymsfield SB: Models use leptin and calculus to count calories. Cell Metab 2009, 9:3-4.

2. Leibel RL: Molecular physiology of weight regulation in mice and humans. Intern J Obes 2008, 32:S98-SI08.

3. Garrow JS: Obesity and Related Diseases. Edinburgh: Churchill Livingstone; 1988.

4. Keys A: The Biology of Human Starvation. Minneapolis, MN: University of Minnesota; 1950.

5. Dulloo AG, Jacquet J, Girardier L: Poststarvation hyperphagia and body fat overshooting in humans: a role for feedback signals from lean and fat tissues. Am J Clin Nutr 1997, 65:717-23.

6. Hall KD: Computational model of in vivo energy metabolism during semistarvation and refeeding. Am J Physiol Endocrinol Metab 2006, 29I:E23-37.

7. Hall KD: Predicting metabolic adaptation, body weight change, and energy intake in humans. Am J Physiol Endocrinol Metab 2010, 298:E449-66.

8. Svetkey LP, Stevens VJ, Brantley PJ, Appel LJ, Hollis JF, Loria CM, Vollmer WM, Gullion CM, Funk K, Smith P, Samuel-Hodge C, Myers V, Lien LF, Laferriere D, Kennedy B, Jerome GJ, Heinith F, Harsha DW, Evans P, Erlinger TP, Dalcin AT, Coughlin J, Charleston J, Champagne CM, Bauck A, Ard JD, Aicher K; Weight Loss Maintenance Collaborative Research Group: Comparison of strategies for sustaining weight loss: the weight loss maintenance randomized controlled trial. JAMA 2008, 299: I |39-48.

9. Pi-Sunyer FX, Aronne LJ, Heshmati HM, Devin J, Rosenstock J; RIO-North America Study Group: Effect of rimonabant, a cannaboid-I receptor blocker, on weight and cardiometabolic risk factors in overweight or obese patients: RIO-North America: a randomized controlled trial. JAMA 2006, 295:76I-75.

10. Walley AJ, Asher JE, Froguel P: The genetic contribution to nonsyndromic human obesity. Nat Rev Genet 2009, 10:43 I-42.

FI000 Factor 6.0 Must Read

Evaluated by Anke Hinney 07 Sep 2009

I I. Kral JG, Biron S, Simard S, Hould F-S, Lebel S, Marceau S, Marceau P: Large maternal weight loss from obesity surgery prevents transmission of obesity to children who were followed for 2 to 18 years. Pediatrics 2006, I I 8:e I644-9.

12. Later W, Bosy-Westphal A, Hitze B, Kossel E, Glüer CC, Heller M, Müller MJ: No evidence of mass dependency of specific organ metabolic rate in healthy humans. Am J Clin Nutr 2008, 88: 1004-9.

13. Müller MJ, Bosy-Westphal A, Krawczak M: Genetic studies of common types of obesity: a critique of the current use of phenotypes. Obes Rev 2010, I I:612-8.
14. Mauer MM, Harris RBS, Bartness TJ: The regulation of body fat: lessons learned from lipectomy studies. Neurosci Biobehav Rev 2001, 25:15-28.

I5. O'Rahilly S, Farooqi IS: Human obesity as a heritable disorder of the central control of energy balance. Int J Obes 2008, 32:S55S6I.

16. Jansen J, Fortier A, Hudson R, Ross R: Effects of energy-restrictive diet with or without exercise on abdominal fat, intermuscular fat, and metabolic risk factors in obese women. Diabetes Care 2002, 25:431-8.

17. Bosy-Westphal A, Kossel E, Goele K, Blöcker T, Lagerpusch M, Later W, Heller M, Glüer CC, Müller MJ: Association of pericardial fat with liver fat and insulin sensitivity after dietinduced weight loss in overweight women. Obesity (Silver Spring) 2010, [Epub ahead of print].

18. Malis C, Rasmussen EL, Poulsen P, Petersen I, Christensen K, BeckNielsen H, Astrup A, Vaag AA: Total and regional fat distribution is strongly influenced by genetic factors in young and elderly twins. Obes Res 2005, 13:2139-45.

19. Redman LM, Heilbronn LK, Martin CK, Alfonso A, Smith SR, Ravussin E; Pennington CALERIE team: Effect of calorie restriction with and without exercise on body composition and fat distribution. J Clin Endocrin Metab 2007, 92:865-72.

20. Chaston TB, Dixon JB: Factors associated with percent change in visceral versus subcutaneous abdominal fat during weight loss: findings from a systematic review. Int J Obes 2008, 32:6 I928.

21. Westerterp KR: Physical activity, food intake, and body weight regulation: insights from doubly labelled water studies. Nutr Rev 2010, 68:148-54.

22. Westerterp K: Alterations in energy balance with exercise. Am J Clin Nutr 1998, 68:970S-974S.

23. Jebb SA, Prentice AM, Goldberg GR, Murgatroyd PR, Black AE, Coward WA: Changes in macronutrient balance during overand underfeeding assessed by I 2 -d continuous whole body calorimetry. Am J Clin Nutr 1996, 64:259-66.

24. Leibel RL, Rosenbaum M, Hirsch J: Changes in energy expenditure resulting from altered body weight. $N$ Engl J Med 1995 , 332:62I-8.

25. Müller MJ, Bosy-Westphal A, Later W, Haas V, Heller M: Functional body composition - insights into regulation of energy metabolism and some clinical applications. Eur J Clin Nutr 2009, 63:1045-56.

26. Redman LM, Heilbronn LK, Martin CK, de Jonge L, Williamson DA, Delany JP, Ravussin E; Pennington CALERIE team: Metabolic and behavioural compensations in response to caloric restriction: implications for the maintenance of weight loss. PLoS One 2009, 4:e4377.

27. Diaz EO, Prentice AM, Goldberg GR, Murgatroyd PR, Coward WA: Metabolic response to experimental overfeeding in lean and overweight healthy volunteers. Am J Clin Nutr 1992, 56:64 I-55.

28. Bosy-Westphal A, Goele K, Later W, Hitze B, Kossel E, Settler U, Heller M, Glüer C-C, Heymsfield SB, Müller MJ: Contribution of individual organ mass loss to weight loss-associated decline in resting energy expenditure. Am J Clin Nutr 2009, 90:993-1001.

29. Jequier E, Tappy L: Regulation of body weight. Physiol Rev 1999, 79:45I-80.

30. Flatt JP: Carbohydrate balance and body-weight regulation. Proc Nutr Soc 1996, 55:449-65.

31. Astrup A, Flatt JP: Metabolic determinants of body weight regulation. In Regulation of Body Weight: Biological and Behavioural Mechanisms. Edited by Bouchard C, Bray GA. Chichester: John Wiley \& Sons; 1996:193-210.

32. Flatt JP, Ravussin E, Acheson KJ, Jequier E: Effects of dietary fat on postprandial substrate oxidation and carbohydrate and fat balances. J Clin Invest 1985, 76:1019-24.

33. Prentice AM: Manipulation of dietary fat and energy density and subsequent effects on substrate flux and food intake. $\mathrm{Am} J$ Clin Nutr 1998, 67:535S-54IS. 
34. Coleman DL: Obese and diabetes: two mutant genes causing diabetes-obesity syndromes in mice. Diabetologia 1978, I4: |4 I-8.

35. Friedman JM: Leptin at I4y of age: an ongoing story. Am J Clin Nutr 2009, 89(Suppl):973S-979S.

36. Blüher S, Mantzoros CS: Leptin in humans: lessons from translational research. Am J Clin Nutr 2009, 89(Suppl):99IS-997S.

37. Prentice AM, Moore SE, Collinson AC, O'Connell MA: Leptin and undernutrition. Nutr Rev 2002, 60:S56-S67.

38. Tam J, Fukumura D, Jain RK: A mathematical model of murine metabolic regulation by leptin: energy balance and defense of a stable body weight. Cell Metab 2009, 9:52-63.

39. Rosenbaum M, Goldsmith R, Bloomfield D, Magnano A, Weimer L, Heymsfield S, Gallagher D, Mayer L, Murphy E, Leibel RL: Low-dose leptin reverses skeletal muscle autonomic, and neuoendorine adaptations to maintenance of reduced weight. J Clin Invest 2005, I | 5:3579-86.

40. Haas V, Gaskin KJ, Kohn MR, Clarke SD, Müller MJ: Different thermic effects of leptin in adolescent females with varying body fat content. Clin Nutr 2010, [Epub ahead of print].

41. Swinburn B, Egger $G$ : The runaway weight gain train: too many accelerators, not enough breaks. BMJ 2004, 329:736-9.

42. Plachta-Danielzik S, Landsberg B, Bosy-Westphal A, Johannsen M, Lange $D$, Müller MJ: Energy gain and energy gap in normalweight children: longitudinal data of the KOPS. Obesity (Silver Spring) 2008, 16:777-83.
43. Hill JO, Wyatt HR, Reed GW, Peters JC: Obesity and the environment: where do we go from here? Science 2003, 299:853-5.

44. Ravussin E, Lillioja S, Knowler WC, Christin L, Freymond D, Abbott WGH, Boyce V, Howard BV, Bogardus C: Reduced rate of energy expenditure as a risk factor for body weight gain. N Engl J Med 1988, 3 I 8:467-82.

45. Rothwell NJ, Stock MJ: A role for brown adipose tissue in dietinduced thermogenesis. Nature 1979, 281:3|-5.

46. Prentice AM, Poppitt SD: Importance of energy density and macronutrients in the regulation of energy intake. Int J Obes 1996, 20(Suppl 2): S18-S23.

47. Pasquet $P$, Apfelbaum $M$ : Recovery of initial body weight and composition after long-term massive overfeeding in men. Am J Clin Nutr 1994, 60:86I-3.

48. Prentice AM, Jebb SA, Goldberg GR, Coward WA, Murgatroyd PR, Poppitt SD, Cole TJ: Effects of weight cycling on body composition. Am J Clin Nutr 1992, 56:209S-216S.

49. Hall KD, Baracos VE: Computational modelling of cancer cachexia. Curr Opinion Clin Nutr Metab Care 2008, I I:2I4-2I.

50. Peters JC, Wyatt HR, Donahoo WT, Hill JO: From instinct to intellect: the challenge of maintaining healthy weight in the modern world. Obes Rev 2002, 3:69-74.

51. Courcier EA, Thomson RM, Mellor DJ, Yam PS: An epidemiological study of environmental factors associated with canine obesity. J Small Anim Pract 2010, 5 I:362-7. 